\title{
Deep-sea mining of seafloor massive sulfides
}

\section{Porter Hoagland $^{\mathrm{a} *}$, Stace Beaulieu ${ }^{\mathrm{b}}$, Maurice A. Tivey ${ }^{\mathrm{c}}$, Roderick G. Eggert ${ }^{\mathrm{d}}$, Christopher German', Lyle Glowka ${ }^{\mathrm{e}}$ and Jian Lin ${ }^{\mathrm{c}}$}

${ }^{a}$ Marine Policy Center, MS\#41, Woods Hole Oceanographic Institution, Woods Hole, MA 02543, USA.

${ }^{b}$ Department of Biology, MS\#7, Woods Hole Oceanographic Institution, Woods Hole, MA 02543, USA.

${ }^{c}$ Department of Geology \& Geophysics, MS\#24, Woods Hole Oceanographic Institution, Woods Hole, MA 02543, USA.

${ }^{d}$ Division of Economics \& Business, Colorado School of Mines, 816 15th Street, Golden, Colorado 80401, USA.

${ }^{e}$ Social, Economic and Legal Matters, Convention on Biological Diversity, 413 Saint Jacques Street, Montreal, QC H2Y 1N9, Canada.

*Corresponding author: phone: +1 508289 2867; fax: +1 508457 2184; email address: phoagland@whoi.edu. 


\section{$\underline{\text { Abstract }}$}

The potential emergence of an ocean mining industry to exploit seafloor massive sulfides could present opportunities for oceanographic science to facilitate seafloor mineral development in ways that lessen environmental harms. 
Recent economic growth in China, ranging from 6 to $9 \%$ during the first three quarters of 2009, seems barely influenced by the worldwide recession [1]. This growth has been driven not by traditional export markets, which have experienced significant contractions, but by local demand for automobiles and real estate. China and other emerging economies continue to look for new sources of minerals and materials to maintain this growth, and this search could bring on increased exploration for unusual resources, such as the seafloor base metal sulfide minerals found at mid-ocean ridges and back-arc basins. The unique but ephemeral ecologies affiliated with these mineral occurrences imply a need to tradeoff economic development and environmental protection. Even so, opportunities for oceanographic science to mitigate this essential conflict have begun to emerge.

Attention is being directed increasingly now at the likely emergence of a new industry in the oceans: underwater mining. Unlike earlier attempts to recover manganese nodules from the abyss [2], commercial interests currently are focusing on seafloor massive sulfides (SMS) located in back-arc basins and arc volcanoes on convergent plate boundaries at the shallower water depths of $\leq 2 \mathrm{~km}$ [3]. Many questions exist about the environmental sustainability of underwater mining, however, and public policies are under development to assess impacts, protect ecosystems, and distribute resource rents. These policies are as yet inchoate, and oceanography may help shed light on the relevant questions, thereby increasing the likelihood that seafloor mineral occurrences become economic reserves.

SMS are base metal $(\mathrm{Fe}, \mathrm{Cu}, \mathrm{Zn}, \mathrm{Pb})$, sulfur-rich mineral deposits that precipitate from hydrothermal fluid as it interacts with the cooler ambient seawater at or beneath the seafloor at hydrothermal vent sites. SMS deposits are found in as many as a dozen different tectonic settings but most occur on the almost 60,000 km long mid-ocean ridge system, the 22,000 km of 
volcanic arcs, or the 7,000 km of back-arc spreading systems, where estimates suggest they may be spaced on average $100 \mathrm{~km}$ apart. Up to $40 \%$ of the known deposits occur at shallower depths in back-arc basins and on submarine volcanic ridges within 200 nautical miles of the coast and within the jurisdiction of national exclusive economic zones (EEZs). There may be as many as 1,000 active seafloor hydrothermal sites worldwide, but systematic exploration for active sites along the global ridge-crest remains limited [4], and a database maintained by the International Seabed Authority (ISA) currently lists only 327 active and inactive sites that have been documented to date [5]. At present, only about 100 of these hydrothermal sites are known to host significant SMS mineralization.

In order to become commercial prospects, SMS deposits must be able to compete with land-based supplies on the basis of advantages in size, grade, or accessibility [6]. In terms of size, SMS deposits tend to be smaller than their onshore counterparts, many of which were formed in comparable but much more ancient subsea environments. The typical large deposit found onshore is on the order of 50 to $60 \mathrm{Mt}$, but the likelihood of discovering this size of deposit on the seafloor appears small, where most deposits found to date are in the 1 to $5 \mathrm{Mt}$ range. The metalliferous muds of the Atlantis II Deep in the Red Sea (90 Mt) may be the only SMS deposit similar in scale to the large onshore deposits. Geologic theories suggest that other mega-deposits could be buried under continental sediments [5], but these deposits may be both technically challenging and costly to find.

Based upon limited and unsystematic sampling, the metal contents (grades) of some SMS deposits appear highly attractive [7]. SMS typically are comprised of iron pyrite and base metal sulfide minerals, including chalcopyrite, sphalerite, and galena. Copper and zinc are the most likely metals to be recovered from SMS, but some deposits exhibit significant gold (0-20 ppm) 
and silver (0-1200 ppm) grades as well. Substantial variability in metal values occurs at local and regional scales, however, and it can be both technically problematic and costly to sample the friable SMS deposits for size and grade. Notwithstanding the presence of grade risk, Nautilus Minerals Inc., one of the few firms in the nascent seafloor mining industry, cites assayed grades within SMS deposits sampled off Papua New Guinea as follows: copper (6.8\%), zinc (0.4\%), gold (4.8 ppm), and silver (23 ppm) [8]. The indicated massive sulfide resource for the Solwara1 site is $0.87 \mathrm{Mt}$ with $1.3 \mathrm{Mt}$ of inferred resource.

Advantageous conditions in the markets for the metals occurring in SMS deposits, including copper, zinc, and gold, eventually may call these deposits into production. The 20032008 boom in commodity prices sparked interest in possible development of SMS deposits. Over the longer term, however, prices for non-ferrous minerals have been fairly flat (Fig. 1). Whether they exhibit any upward or downward trend, and thus signal worldwide resource depletion, is sensitive to the choice of price deflator [9]. Whether recent price surges were evidence of secular changes in the metals markets or merely fleeting cycles is a subject of debate among economists. There is evidence for secular metals price increases as the result of economic development in China and other developing countries. Restrictions on the supply of metals, including environmental constraints on the availability of onshore mine expansions and openings, also tend to support higher prices. Further exploration and discoveries, cost-reducing technological advances, recycling, and conservation in the face of rising prices are factors that work against secular increases. For example, there is little evidence of secular or persistent increases in the marginal costs of production at working copper mines, beyond those increases that are cyclical due to the temporary bidding-up of input costs [10]. 
A clearer understanding of the market structure, mining firm conduct, and economic performance of the markets for non-ferrous metals could clarify our understanding of the economic potential of SMS deposits [11]. For manganese nodules in the 1970s and 1980s, strategic behavior among firms clearly motivated early prospecting and exploration efforts for a resource that remains uneconomic decades hence [6]. Similar behavior now may be taking place among firms focused on SMS. Larger mining companies, such as Anglo American and Teck, may be investing in SMS because of early-mover advantages, such as access to superior resources that may not be available later; the development of technological capabilities that will be difficult for rivals to imitate without cost in the future (e.g., due to intellectual property protection); or the efficiencies that firms achieve through experience.

The international institutions governing access to SMS are only beginning to take shape. Marine scientific research is still a high seas freedom, but it is subject to a regime requiring the prior consent of the adjacent coastal state within its EEZ and on its continental shelf. Beginning almost half a century ago, decades of deliberations went into the third United Nations Convention on the Law of the Sea (UNCLOS), a subsequent revision to its deep seabed mining regime, and the promulgation of regulations concerning the prospecting for and exploration of manganese nodules. Although extensive prospecting and technological development for manganese nodules has taken place, only central governments or their agencies appear prepared to shoulder the risks involved in carrying out license requirements. In particular, these governments may be concerned more with the hope of securing stable metal supplies than with the expectation of profitable mining operations.

UNCLOS established an International Seabed Authority (ISA) with responsibilities for developing and overseeing regulations governing the issuance of prospecting, exploration, and, 
eventually, extraction licenses for minerals in the deep seabed beyond national jurisdiction, known as the Area. Regulations pertaining to manganese nodules have been put in place already, and several licenses have been issued [2,3]. Differences in the occurrence and distribution of SMS deposits imply the need for implementing a different system of access for their prospecting and exploration [12]. Draft regulations for SMS were released by ISA in 2007, but there have been ongoing delays in making them final. According to ISA, one cause for delay is the dearth of scientific information about non-active hydrothermal vent sites. Without such information, characterizing the potential environmental effects of mineral development is problematic. Without exploration permits, however, the industry is unable to access the sites to begin generating environmental baselines. This predicament bodes ill for SMS development in the Area, unless national governments demonstrate a willingness to invest in basic science that can contribute to environmental assessments at both the active hydrothermal vent sites and, especially, the seemingly comparatively uninteresting inactive sites.

Among other factors, including mandates to transfer technologies and to share revenues with the international community, the absence of a clearly defined regulatory regime for the Area has likely encouraged commercial firms to focus their prospecting efforts within national EEZs, where access regimes are relatively clearer and the legal risks smaller. An ability to objectively assess the nature of the tradeoffs between local economic development and the threats to unique marine ecosystems is a critical issue for SMS development in developed and developing countries alike. The interface between SMS mining and environmental protection will be particularly challenging for developing countries, such as Papua New Guinea or Tonga, however, because of their limited capacities to undertake appropriate environmental assessments and to develop and enforce suitable environmental laws to oversee seafloor mining activities 
effectively. Without such technical, legal, and institutional capacities, serious and potentially irreversible environmental damage could occur.

The emergence of a voluntary instrument called the Code for Environmental Management of Marine Mining [13] may help to fill policy voids at both national and international levels [14]. Initially proposed in 2000 by Nautilus Minerals, and under development by the International Marine Minerals Society, the Code's current draft revision articulates principles and operating guidelines for the responsible and sustainable development of underwater mining. Following the lead of the 1992 Rio Declaration [15], the Code calls for forming community partnerships, undertaking environmental quality reviews, adopting strategies for risk management, urging firms to espouse ethical business practices, developing environmental performance targets, and observing a precautionary principle. The latter is especially noteworthy, although its definition is more dilute than that which emerged from Rio, encompassing only the "reasonable likelihood" of serious or irreversible harm to the marine environment, and invoking no risk-benefit or cost-effectiveness tests for taking actions to avoid potential harm.

The Code has already been applied in rather innovative ways to SMS deposits. For example, Nautilus Minerals' plan for exploiting the Solwara-1 site in the Manus Basin off Papua New Guinea is to crush the ore on the seabed, lift it hydraulically to a surface vessel, dewater the ore, and pump the fluid back to the seafloor, with the aim of minimizing impacts to pelagic ecosystems (Fig. 2). Mining is planned to proceed alongside unmined control areas, evincing an arguably precautionary approach [16] that has been designed to produce knowledge about potential ecological changes [14]. For example, given the geologically ephemeral nature of active hydrothermal vents and associated communities, undertaking scientific experimentation in 
concert with mineral extraction could lead to insights about the potential for and the rate and extent of biotic recolonizations [17].

Because scientific understandings of the processes of formation and evolution of SMS deposits and the functioning of their affiliated ecosystems are still emergent, opportunities exist for oceanographic science to proceed apace with industry and to inform it in a way that facilitates industrial exploration while mitigating environmental harm. The interdisciplinary Seafloor Mineralization Working Group, established by InterRidge [18] in 2008, takes as one premise that science, industry, and other concerned parties have complementary roles to play. The Working Group has identified three general categories of research needs: characterizing the spatial controls on hydrothermal activity and SMS deposition; estimating the timescales for SMS deposit evolution; and observing the changes in biological communities that occur during SMS deposit evolution [19]. Research advances in all three categories are likely to be of immense value to industrial development in the field of underwater mining. Oceanographic science also is likely to benefit from the increased attention, the surfacing of interesting research questions, and the development of research opportunities as underwater mining starts to mature.

\section{Acknowledgements}

The authors are grateful for support from the Elisabeth and Henry Morss, Jr. Colloquia Fund, the ChEss (Chemosynthetic Ecosystems) Project of the Census of Marine Life, InterRidge, the Ridge 2000 Program of the National Science Foundation, and the authors' institutions. 


\section{References}

[1] National Bureau of Statistics of China. Beijing: NBSC; 2009; http://www.stats.gov.cn/ english/statisticaldata/Quarterlydata/.

[2] Glasby G.P. Lessons learned from deep-sea mining. Science 2000; 289: 551-553.

[3] Rona P. Resources of the sea floor. Science 2003; 299: 673-674.

[4] Baker ET, German CR. On the global distribution of mid-ocean ridge hydrothermal ventfields. Geophysical Monographs 2004; 148: 245-266.

[5] Hannington MD, deRonde CEJ, Petersen S. Sea-floor tectonics and submarine hydrothermal systems. Economic Geology 2005; 100: 111-141.

[6] Broadus JM. Seabed materials. Science 1987; 235: 853-860.

[7] Tivey MA. Deep-sea mining of seafloor massive sulfides: a reality for science and society in the $21^{\text {st }}$ century. Woods Hole: Woods Hole Oceanographic Institution; 2009; http://www.whoi.edu/page.do?pid=28896.

[8] Golder Associates. Mineral resource estimate, Solwara 1 Project, Bismarck Sea, Papua New Guinea. Toronto: Nautilus Minerals Inc.; 2008; http://www.nautilusminerals.com/s/Home.asp.

[9] Svedberg P, Tilton JE. The real, real price of nonrenewable resources: copper 1870-2000. World Development 2006; 34: 501-519.

[10] Eggert RG. Economic perspectives on seabed mining. Woods Hole: Woods Hole Oceanographic Institution; 2009; http://www.whoi.edu/page.do?pid=28896.

[11] Crowson P. The copper industry 1945-1975. Resources Policy 2007; 32: 1-18.

[12] Hannington MD, Monecke T. Global exploration models for polymetallic sulphides in the area: an assessment of lease block selection under the draft regulations on prospecting and 
exploration for polymetallic sulphides. Marine Georesources and Geotechnology 2009; 27: 132-159.

[13] Code for Environmental Management of Marine Mining, Draft Revision as of 21 August 2009. Honolulu: IMMS; 2009; http://www.immsoc.org/IMMS code.htm.

[14] Verlaan P. Experimental activities that intentionally perturb the marine environment: implications for the marine environmental protection and marine scientific research provisions of the 1982 United Nations Convention on the Law of the Sea. Marine Policy 2007; 31: 210-216.

[15] Rio Declaration on Environment and Development. Nairobi: UNEP; 1992; http://www.unep.org/Documents.Multilingual/Default.asp?DocumentID=78\&ArticleID=1 $\underline{163 .}$.

[16] Halfar J, Fujita RM. Precautionary management of deep-sea mining. Marine Policy 2002; 26: 103-106.

[17] Van Dover CL, Lutz RA. Experimental ecology at deep-sea hydrothermal vents: a perspective. Journal of Experimental Marine Biology and Ecology 2004; 300: 273-307.

[18] InterRidge is an international organization of academic researchers that promotes interdisciplinary studies of oceanic spreading centers by creating a global research community, planning and coordinating new science programs that no single nation can achieve alone, exchanging scientific information, and sharing new technologies and facilities. InterRidge reaches out to the public, scientists, and governments, providing a unified voice for ocean ridge researchers worldwide; http://www.interridge.org.

[19] Seafloor Mineralization Working Group, 2009 Meeting Report. Woods Hole: InterRidge; 2009; http://www.interridge.org/en/node/5797. 
[20] US Geological Survey. Mineral Commodity Summaries. Reston: USGS; 1998-2009; http://minerals.usgs.gov/minerals/pubs/mcs/. U.S. Geological Survey, Metal Prices in the United States through 1998. Reston: USGS; 1998; http://minerals.usgs.gov/minerals/pubs/metal prices/.

[21] Bureau of Economic Analysis. National Income and Product Accounts Table 1.1.9, Implicit Price Deflators for Gross Domestic Product. Washington: Bureau of Economic Analysis; 2009; http://www.bea.gov/national/ nipaweb/.

[22] Environmental Impact Statement, Solwara 1 Project, Vol. A. Brisbane: Coffey Natural Systems Pty. Ltd.; 2008; http://www.cares.nautilusminerals.com/.

\section{Figure Captions}

Fig. 1. Long-term real price indexes for: (a) copper and (b) zinc. The indexes show flat, naïve linear (dashed line) and cubic (solid line) longterm trends, even with intermittent price runups. Price data are from the US Geological Survey [20], as adjusted by the implicit price deflator for US gross domestic product from the US Bureau of Economic Analysis [21].

Fig. 2. Schematic of SMS mining technology and plan for the Solwara 1 deposit off Papua New Guinea [22]. 
A

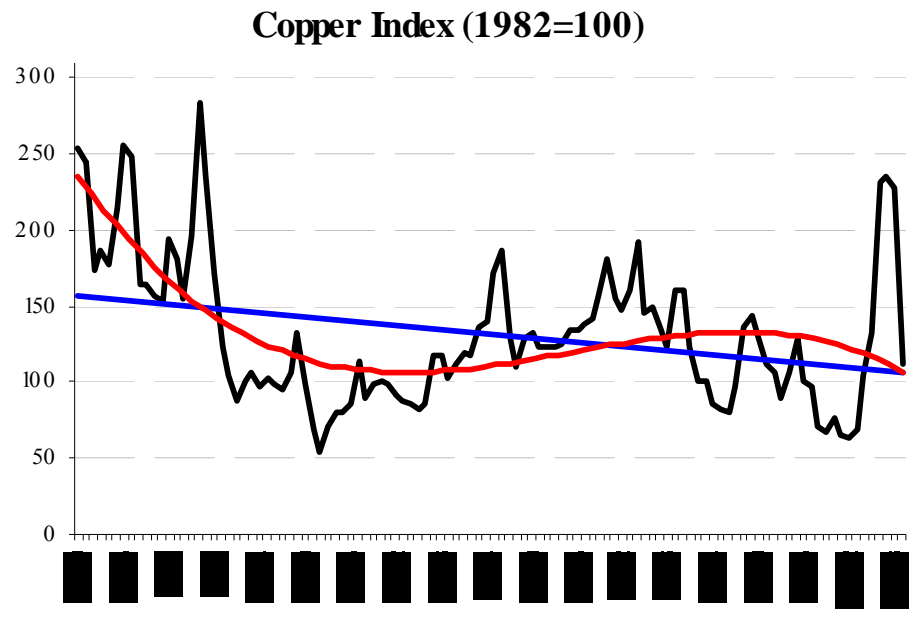

B

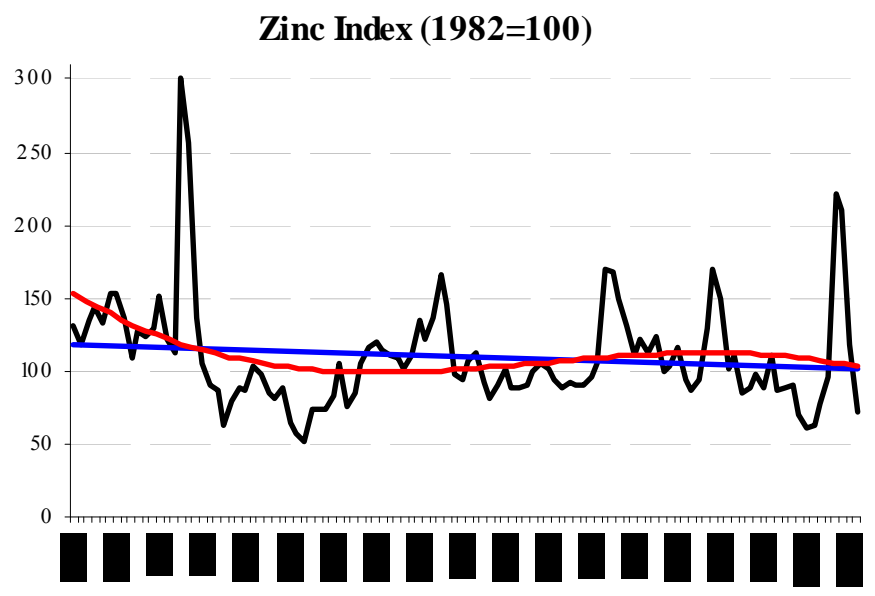

Figure 1 


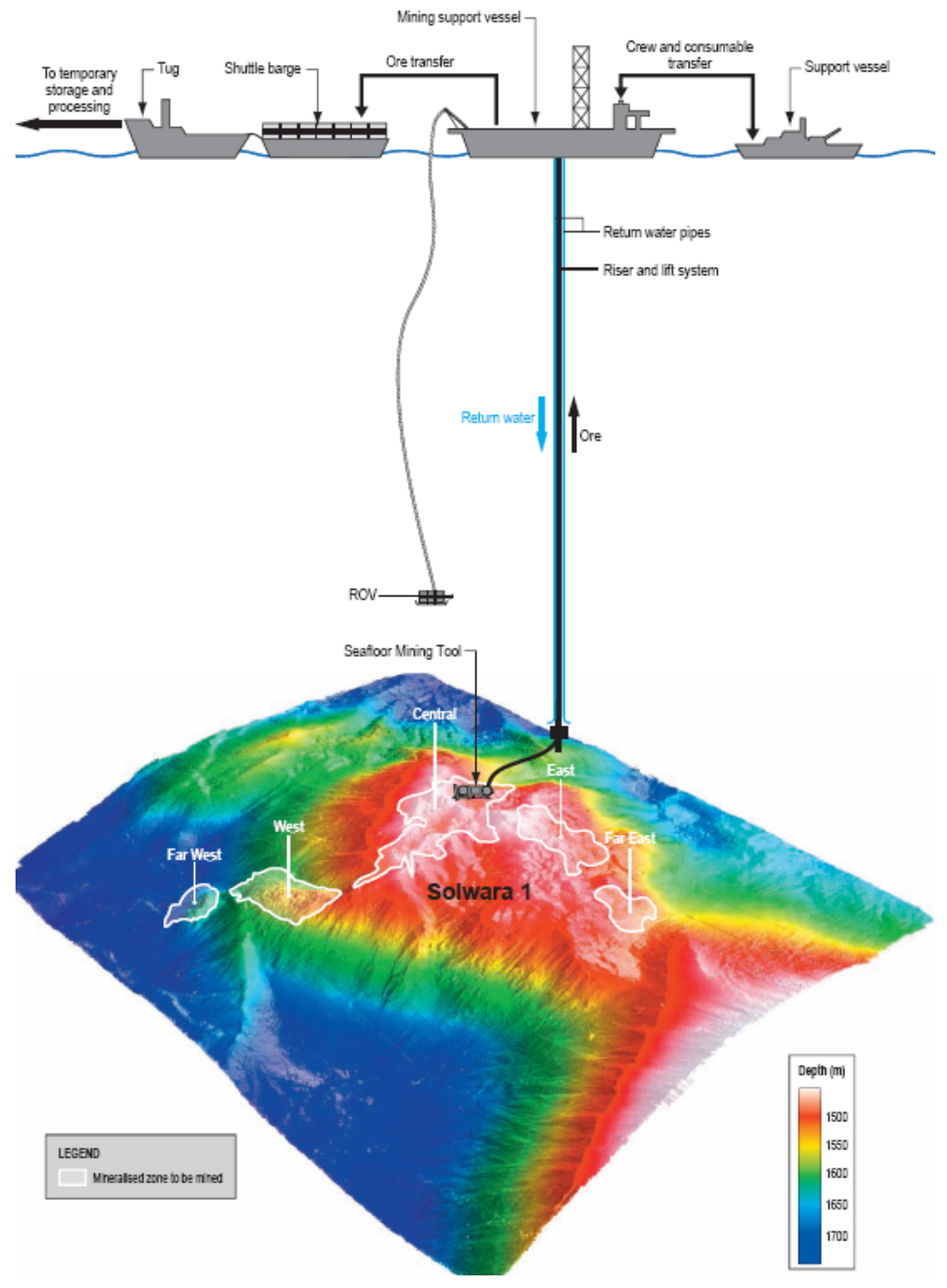

Figure 2 